Article

\title{
Hydrogen Storage Properties of Mg-Ni Alloys Processed by Fast Forging
}

\author{
Patricia de Rango ${ }^{1, *}{ }^{\circledR}$, Jing Wen ${ }^{1}$, Nataliya Skryabina ${ }^{2}$, Laetitia Laversenne ${ }^{1}(\mathbb{D}$, \\ Daniel Fruchart ${ }^{1}$ and Marielle Borges ${ }^{1}$ \\ 1 University Grenoble Alpes, CNRS, Institut Néel, 38000 Grenoble, France; jing.wen@neel.cnrs.fr (J.W.); \\ laetitia.laversenne@neel.cnrs.fr (L.L.); daniel.fruchart@orange.fr (D.F.); marielleborgesm@gmail.com (M.B.) \\ 2 Department of Physics, Perm State University, 15 Bukireva, 614990 Perm, Russia; natskryabina@mail.ru \\ * Correspondence: patricia.derango@neel.cnrs.fr
}

Received: 20 May 2020; Accepted: 3 July 2020; Published: 7 July 2020

check for updates

\begin{abstract}
Fast forging of compacts made up of Mg and Ni powders is shown to be an effective method to induce severe plastic deformation with improved $\mathrm{H}_{2}$ sorption properties. Here, using such processed samples, a comprehensive analysis of the sorption properties reveals that the first hydrogenation sequence significantly depends on the forging temperature, through different microstructures. More in detail, no phase transformation occurs upon cold forging, while solid-state reaction leads to the formation of the $\mathrm{Mg}_{2} \mathrm{Ni}$ intermetallic compound upon forging above $400^{\circ} \mathrm{C}$. Forging below the brittle-to-ductile transition $\left(225-250^{\circ} \mathrm{C}\right.$ ) leads to faster $\mathrm{H}_{2}$ uptake upon first absorption owing to a more textured fiber along the c-axis and internal strains which promote hydrogen diffusion through the bulk material. Desorption kinetics remain slower with low-temperature forging, despite $\mathrm{Ni}$ recombining to form $\mathrm{Mg}_{2} \mathrm{Ni}$ during the first desorption. After several cycles, a two-step behavior is observed with a fast absorption step occurring up to about $3 \mathrm{wt} . \%$. Despite this limited uptake performance, the forging process can be considered as a straightforward, safe, and cost-efficient process to produce large amounts of Mg-based alloys for hydrogen storage. In particular, such severe plastic deformation processes can be considered as reliable substitutes for ball-milling, which is highly efficient but energy- and time-consuming.
\end{abstract}

Keywords: hydrogen storage; metal hydrides; $\mathrm{Mg}-\mathrm{Ni}$; eutectic alloys; severe plastic deformation; forging

\section{Introduction}

Among the materials relevant for solid hydrogen storage, magnesium hydride $\left(\mathrm{MgH}_{2}\right)$ stands out thanks to its high reversible hydrogen capacity and raw material availability [1]. Many studies have been devoted to magnesium hydrides and magnesium-based alloys to better understand and overcome their poor sorption kinetics which are detrimental for practical applications. With this aim, among processes that potentially improve hydrogen sorption properties, high-energy ball milling (HEBM) of $\mathrm{MgH}_{2}$ powders-with or without the addition of transition metals-is broadly considered [2-4]. The resulting performance enhancement has been explained by a boosted hydrogen diffusion in the material resulting from the combination of reduced grain size, higher density of structural defects, and larger reactive surface area. However, the first hydrogenation of $\mathrm{Mg}$, which is essential to produce the precursor $\mathrm{MgH}_{2}$, remains very slow and requires high temperature $\left(>350{ }^{\circ} \mathrm{C}\right)$ and pressure up to $3 \mathrm{MPa}$ [5]. Moreover, when large-scale production is desired, both the high pressure required for the first hydrogenation step and the HEBM process are prohibitive as they are time- and energy-consuming, and require significant manpower. Finally, handling such pyrophoric powders raises stringent safety concerns. 
Microstructure tuning to achieve enhanced $\mathrm{H}_{2}$ storage can also be performed by means of severe plastic deformation (SPD). In particular, processes such as equal channel angular pressing (ECAP) [6-10], cold rolling (CR) [7,11] and high-pressure torsion (HPT) [12,13] have been carried out. The expected benefits of SPD are shorter processing durations and reduced costs for a safe production of bulk materials resistant to air during manufacture. SPD has been applied to pure $\mathrm{Mg}$ and commercial Mg alloys such as AZ31 or ZK60. Interestingly, some works have shown that SPD processing leads to higher performances in commercial alloys than in pure $\mathrm{Mg}$ [11]. Such results are very promising since further reduction of the production costs are foreseen upon using commercial $\mathrm{Mg}$ alloys.

The main feature that distinguishes SPD from HEBM is the possibility to produce more textured samples with the former process. The beneficial impact of a more pronounced texture on hydrogen sorption properties was evidenced for AZ31 samples processed by ECAP [8]. In this study, the authors cut two pieces with large surfaces and thin thickness, in two perpendicular directions. They achieved much faster kinetics for the surface corresponding to a strong basal (0001) orientation than with the perpendicular surface. The overall hydrogen sorption performances remained, however, limited due to the reduced porosity of the processed materials (leading to poor hydrogen penetration). In contrast, faster kinetics and shorter incubation times were achieved for samples obtained by combining ECAP and CR $[14,15]$. These encouraging results were ascribed to a more pronounced texture together with a reduced sample thickness. Nevertheless, it is worth noting that such samples require a large number of processes-typically 4 to 6 ECAP followed by 20 to 30 CR [14]. In addition, a final mechanical grinding or filling step-needed to increase the surface to volume ratio-is required to obtain samples with fast hydrogen sorption kinetics [16,17]. Therefore, the expected benefits from SPD processes in terms of production, upscaling, and reduced oxidation are counterbalanced by the increased number of processing steps.

Adding nickel to $\mathrm{Mg}$-based samples proved to enhance their hydrogen storage performances. According to [18], $\mathrm{Mg}_{2} \mathrm{NiH}_{4}$ is expected to act as catalyst in $\mathrm{MgH}_{2}$ desorption mechanism. As far as SPD applied to Mg-Ni alloys is concerned, ECAP was applied to as-cast Mg-rich eutectic composition with the aim to induce specific microstructures where $\mathrm{Mg}_{2} \mathrm{Ni}$ brittle lamellae are embedded in $\mathrm{Mg}$ matrix $[19,20]$. ECAP and CR were also applied starting from compacted powders of $\mathrm{Mg}$ and $\mathrm{Ni}$ prepared by HEBM [21] while HPT was applied to $\mathrm{Mg}_{2} \mathrm{Ni}$ ingots [22]. These different studies confirmed the correlation between the change in the microstructure induced by SPD processes and the hydrogen storage properties of $\mathrm{Mg}-\mathrm{Ni}$ alloys.

Forging is an alternative SPD route which has been widely used for centuries in metal factories. Few studies considered the use of forging to improve the sorption kinetics of Mg-based alloys. Starting from $\mathrm{MgH}_{2}$ powders [23,24], a forging process consisting of 10 forging passes in air at room temperature was found to lead to sorption properties similar to those observed on $\mathrm{MgH}_{2}$ powders processed by CR [16] or HPT [25]. For a larger number of forging passes, a partial oxidation of the sample occurs during the forging process. As a result, the thicker samples, which are less sensitive to oxidation, exhibit better properties (shorter incubation time and faster kinetics) [24]. Moreover, the good hydrogen sorption properties obtained under optimal conditions are retained even after several weeks of storage in air. Compared to HEBM, forging is therefore much simpler and less time- and energy-consuming and, more importantly, provides a safe and efficient way to produce bulk hydrogen storage materials in large quantities.

More recently, fast forging (FF) was applied to metallic samples prepared by uniaxial compaction of a mixture of $\mathrm{Mg}$ and Ni powders under eutectic composition. Such a process, which was undertaken to avoid having to synthesize the $\mathrm{MgH}_{2}$ precursor, allows inducing a uniform distribution of $\mathrm{Mg}_{2} \mathrm{Ni}$ particles that could promote the hydrogen diffusion into the $\mathrm{Mg}$ matrix and/or favor a catalytic role in the sorption process [26]. These samples were forged using a single pass at a given temperature up to $530^{\circ} \mathrm{C}$. Interestingly, the $\mathrm{Mg}_{2} \mathrm{Ni}$ phase was formed during the forging process at temperatures as low as $420^{\circ} \mathrm{C}$. Numerical modeling was also performed to estimate the temperature increase induced by the mechanical energy transfer [27]. It was demonstrated that the effective temperature 
is larger than the $\mathrm{Mg}$-Ni eutectic temperature $\left(506^{\circ} \mathrm{C}\right)$, which explains the formation of a $\mathrm{Mg}_{2} \mathrm{Ni}$ phase. The present paper reports on a detailed analysis of the sorption properties of fast forged Mg-Ni samples. In particular, we investigate the first $\mathrm{H}_{2}$ absorption step which is found to strongly depend on the forging temperature. We also establish correlations between hydrogen sorption and solid microstructure. The sorption properties obtained by forging a pure magnesium sample are also presented in this paper to underline the key role of $\mathrm{Ni}$ addition.

\section{Materials and Methods}

Fast forging is performed at the laboratory scale using a homemade forge initially designed for hard magnets processing [28]. The device shown in [26] comprises a chamber under controlled atmosphere and a $150 \mathrm{~kg}$ hammer dropped from a height of $1.5 \mathrm{~m}$ on the upper piston of the chamber at a speed of $4.7 \mathrm{~m} / \mathrm{s}$. The sample, placed on an anvil in the chamber, is heated by means of a retractable high-frequency coil, which is pulled back just before forging (Figure 1a). The temperature is measured using an optical pyrometer with two wavelengths. Only one pass is applied to each sample. Samples were prepared by uniaxial compaction of powder using a pressure of $1 \mathrm{t} / \mathrm{cm}^{2}$. Magnesium powder was supplied by SFM SA in the form of atomized spherical particles of about 3-5 $\mu \mathrm{m}$ and nickel powder by Neco as particles of a few $\mu \mathrm{m}$. All powders were handled in glove box under argon atmosphere. $\mathrm{Mg}-\mathrm{Ni}$ pellets were prepared by manual grinding of these powders according to the composition Mg-10.45 at.\% Ni. This hypoeutectic composition is close to the Mg-rich eutectic Mg- 11.3 at.\% Ni, but slightly lower in $\mathrm{Ni}$ in order to avoid the formation of the $\mathrm{MgNi}_{2}$ phase. The expected hydrogen capacity of these samples is $6 \mathrm{wt} . \%$, corresponding to $1.4 \mathrm{wt} . \%$ as $\mathrm{Mg}_{2} \mathrm{NiH}_{4}+3.6 \mathrm{wt} . \%$ as $\mathrm{MgH}_{2}$ when $\mathrm{Ni}$ is fully recombined with $\mathrm{Mg}$, or $6 \mathrm{wt} . \%$ as $\mathrm{MgH}_{2}$, when $\mathrm{Ni}$ and $\mathrm{Mg}$ are not recombined.
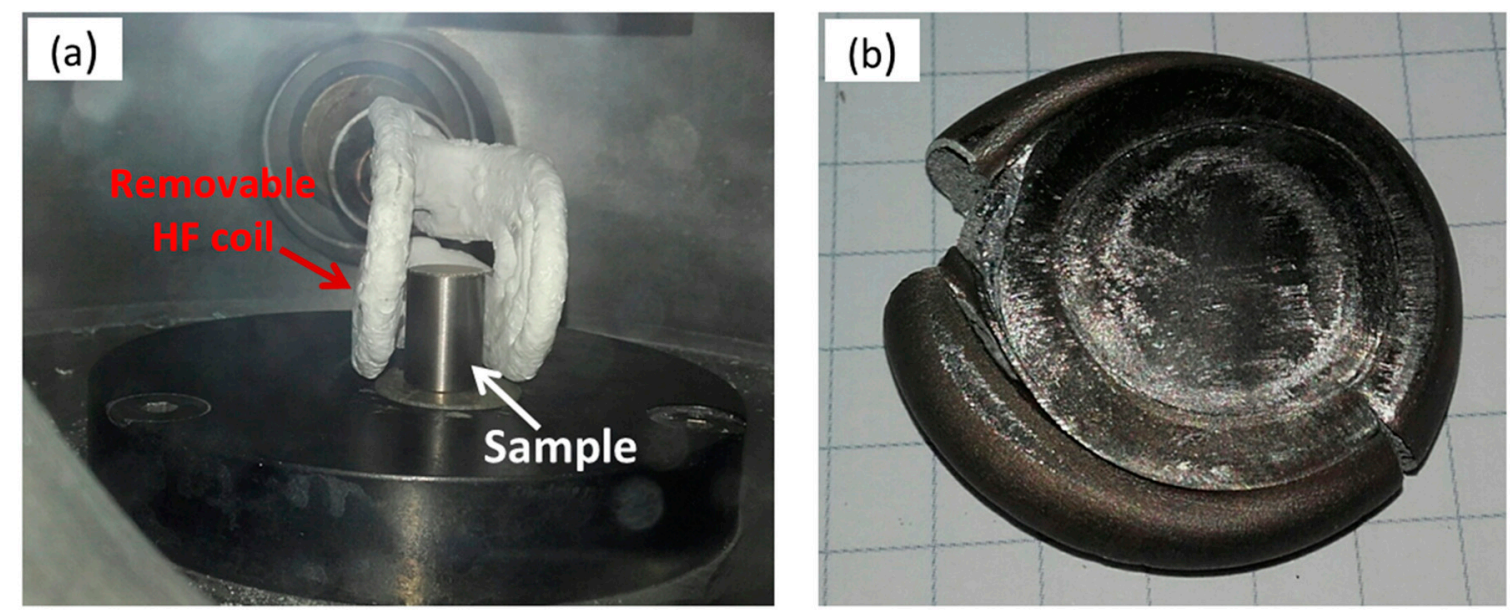

Figure 1. (a) Internal part of the forging chamber, with a sample into the high-frequency heating coil; (b) pure magnesium sample forged at room temperature.

Each sample contained 3 pellets of $13 \mathrm{~mm}$ in diameter, which were introduced into a thin cylindrical stainless-steel tube of $20 \mathrm{~mm}$ high used to contain the material and to prevent its dispersion in the chamber during forging. The total mass of $\mathrm{Mg}$ or $\mathrm{Mg}-10.45 \mathrm{at} . \% \mathrm{Ni}$ was of about $4.5 \mathrm{~g}$ per sample, depending on the composition. The forging process was applied under argon atmosphere at room temperature or at higher temperatures up to $530^{\circ} \mathrm{C}$. Samples were kept for $10 \mathrm{~min}$ at the target temperature to ensure thermal homogeneity. During forging, the height of the sample was reduced from $75 \%$ to $91 \%$, depending on the composition and forging temperature. As shown in Figure $1 \mathrm{~b}$, the forged samples appear in the form of bulk materials surrounded by the steel sheath, which usually splits during forging.

The microstructure of the samples was investigated using a FE-SEM Zeiss Ultra Plus electronic microscope coupled with EDX analysis. The X-ray powder diffraction patterns were performed before 
and after hydrogenation using a Bruker D8 Endeavor diffractometer ( $\mathrm{Cu} \mathrm{K} \alpha$ radiation). Sample compositions, crystallite sizes, and lattice strain of the different phases were determined by Rietveld refinement using the Fullprof program [29]. Hydrogen absorption and desorption kinetics were measured using a volumetric Sievert device from HERA. In this device, the furnace, operated by a hydraulic cylinder, can be removed instantly. This makes it possible to cool down a sample quickly by cooling the sample holder with compressed air. The measurements were all made on a single piece of about $300-500 \mathrm{mg}$ cut in the bulk sample and without any activation process. In this paper, the denomination "pressure cycle" is used for the successive absorption and desorption processes performed isothermally. More in detail, the pressure of hydrogen is set at $2 \mathrm{MPa}$ for absorption and at $15 \mathrm{kPa}$ for desorption. These two steps constitute a so-called pressure cycle, regardless of whether or not the sample absorbs hydrogen. The "reference of zero" for the uptake was reinitialized before each pressure cycle.

\section{Results and Discussion}

\subsection{Pure Magnesium Sample}

A pure $\mathrm{Mg}$ sample prepared from atomized powder was forged at room temperature. Starting from a sample height of $20 \mathrm{~mm}$, a thickness of $4.96 \mathrm{~mm}$ is achieved in one single pass, which corresponds to a reduction ratio of $75 \%$, and an equivalent von Mises $\varepsilon_{\text {eq }}=1.60$.

Figure 2 shows the XRD patterns acquired on polished surfaces (a) on the upper horizontal surface of the forged sample, and (b) on the vertical cross-section obtained by sawing the sample in two equal parts. The relative intensities of the diffraction peaks indicate a strong texture along the c-axis of the $\mathrm{Mg}$ phase for the horizontal surface. This texture was expected since the basal plane $\{0002\}$ is the main slip plane of the hexagonal $\alpha-\mathrm{Mg}$ phase. As reported by Jorge et al. [8], this texture corresponds to the best orientation for hydrogen sorption properties. While the atomized powder supplied by SFM SA consists of well-crystallized spherical particles, the XRD pattern performed after grinding of the forged sample into powder (not shown here) results in broader peak profiles, corresponding to crystallites size reduction $(190 \mathrm{~nm})$ and induced microstrain $(0.14 \%)$.

(a) Horizontal surface

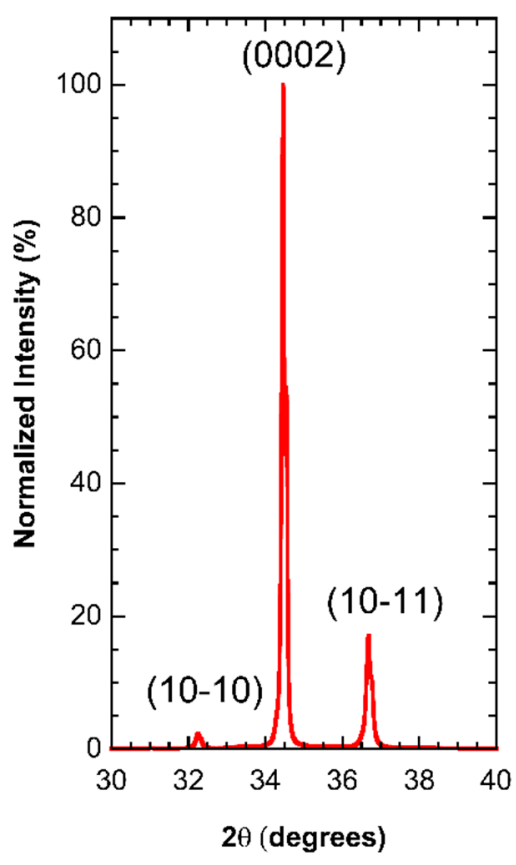

(b) Cross-section

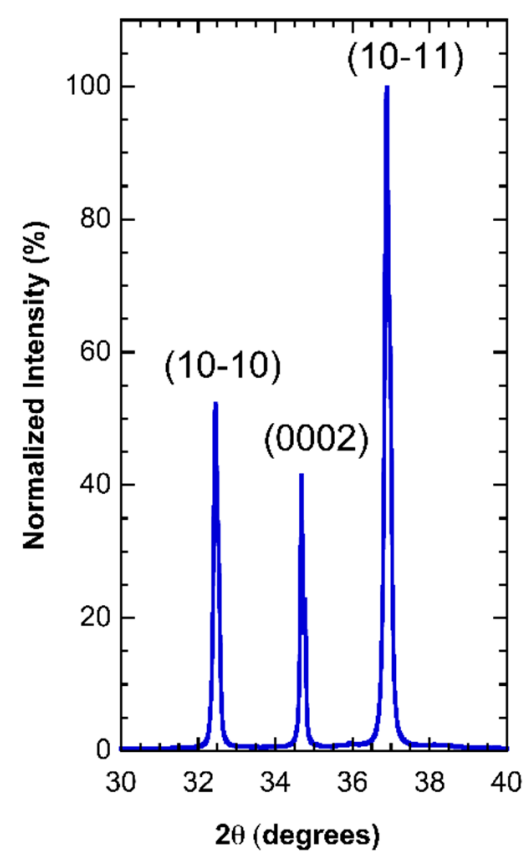

Figure 2. XRD patterns of the pure Mg sample forged at room temperature; (a) horizontal surface of the sample, (b) vertical cross-section. 
It was not possible to hydride this sample at $340{ }^{\circ} \mathrm{C}$ under $2 \mathrm{MPa}$ of hydrogen pressure, even after 10 hydrogen pressure cycles (alternatively $2 \mathrm{MPa}$ and $15 \mathrm{kPa}$ ). It was finally hydrided at $360^{\circ} \mathrm{C}$, but only at the third hydrogen pressure cycle (Figure 3). A hydrogen uptake of $7.4 \mathrm{wt} . \%$ was achieved in $10 \mathrm{~h}$, and the desorption reaction performed under $150 \mathrm{kPa}$ was completed in $2 \mathrm{~h}$ at the same temperature of $360^{\circ} \mathrm{C}$. This difficulty in activating the forged sample, despite obtaining a favorable texture of the $\alpha-\mathrm{Mg}$ phase, probably results from insufficient refinement of the microstructure with a single pass, but also from the fact that the sample obtained after forging was very dense and showed no porosity for the penetration of hydrogen. Even after activation, the following cycles performed at lower temperatures (not shown here) indicated very slow kinetics especially when desorption was performed at $310^{\circ} \mathrm{C}$.

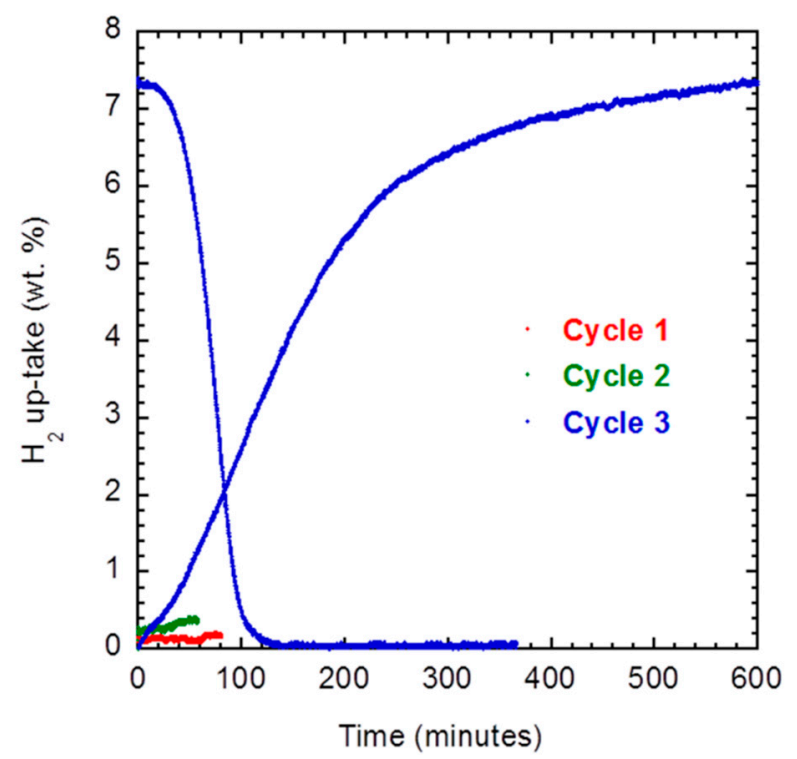

Figure 3. Hydrogen sorption kinetics recorded on a pure $\mathrm{Mg}$ sample forged at room temperature. Hydrogen pressure cycles are applied at $360^{\circ} \mathrm{C}$, with respectively $2 \mathrm{MPa}$ and $150 \mathrm{kPa}$ for absorption and desorption steps.

In practice, when hydrogenation or desorption reactions are applied to a mass of several $100 \mathrm{~g}$ of magnesium, the experimental conditions in the tank tend to the thermodynamic equilibrium conditions [30]. Thus, when a magnesium hydride tank is used to supply a fuel cell with an outlet pressure of about $200 \mathrm{kPa}$, the temperature will immediately reach a value of about $310^{\circ} \mathrm{C}$. Then, cold forging of pure $\mathrm{Mg}$, which leads to very slow kinetics at $310^{\circ} \mathrm{C}$, is not suitable for hydrogen storage.

\subsection{Mg-Ni Eutectic Composition Forged at Room Temperature}

The Mg-10.45 at.\% Ni sample forged at room temperature (RT) led to the same reduction ratio as the sample of pure $\mathrm{Mg}(75 \%)$. The XRD pattern (not shown here) only reveals the presence of the initial $\mathrm{Mg}$ and $\mathrm{Ni}$ phases, without any traces of $\mathrm{Mg}_{2} \mathrm{Ni}$ and the size of the $\mathrm{Mg}$ crystallites calculated from the XRD pattern is similar to that of the pure Mg sample. Figure 4a shows the hydrogen sorption kinetics recorded at $310^{\circ} \mathrm{C}$. Conversely to the behavior of the pure $\mathrm{Mg}$ sample, it was possible to hydride this $\mathrm{Ni}$-containing sample since the first application of hydrogen pressure, without any previous activation process and at a temperature as low as $310^{\circ} \mathrm{C}$. The first absorption did not present any incubation time. Fast initial kinetics were observed up to about $1 \mathrm{wt} . \%$ of hydrogen, and then an acceleration of the reaction took place after about $1 \mathrm{~h}$, to reach a hydrogen uptake of $5.4 \mathrm{wt} . \%$ in $5 \mathrm{~h}$. Desorption was carried out in less than $1 \mathrm{~h}$ at $310^{\circ} \mathrm{C}$ under $150 \mathrm{kPa}$ of hydrogen pressure. However, it was not possible to complete the desorption reaction in these experimental conditions and an irreversible capacity of about $0.2 \mathrm{wt} . \%$ was observed at the end of the first and the second cycles. The following cycles, 
performed in the same experimental conditions, showed a very fast absorption reaction during the first minutes of reaction, followed by a strong reduction of the kinetics, which became even slower than during the first cycle (Figure $4 \mathrm{~b}$ ). Desorption reactions also exhibited a two-stage behavior, with about $1.5 \mathrm{wt} . \%$ desorbed within the 1st minute, and then slower kinetics.
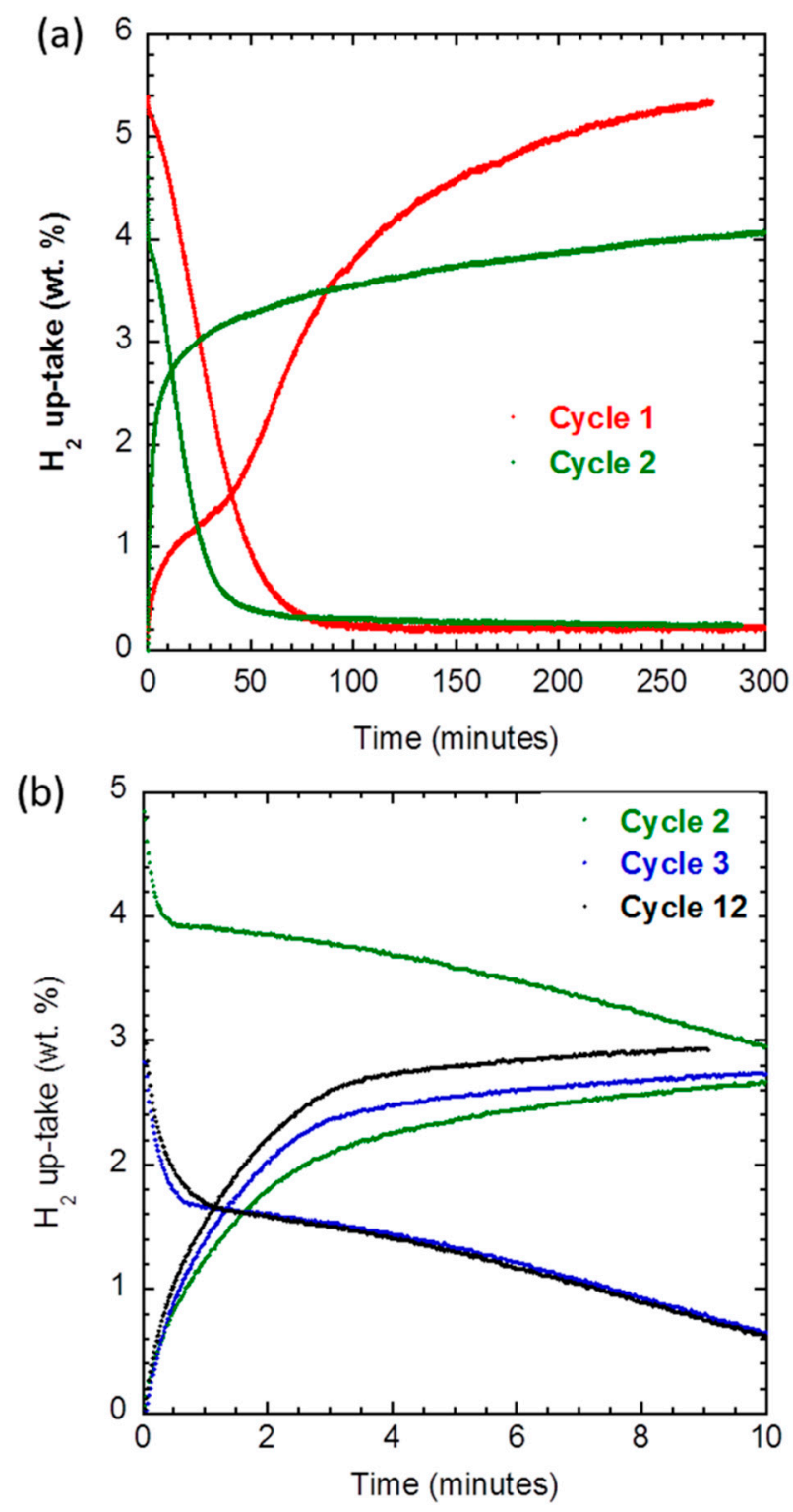

Figure 4. Hydrogen sorption kinetics recorded on Mg-Ni sample forged at room temperature; (a) 1st and 2nd hydrogen cycles, (b) 2nd, 3rd, and 12th hydrogen cycles. Hydrogen pressure cycles are applied at $310^{\circ} \mathrm{C}$, with respectively $2 \mathrm{MPa}$ and $150 \mathrm{kPa}$ for absorption and desorption steps.

Figure 5 shows the XRD patterns recorded after successive absorption and desorption reactions. The weight fractions of each phase obtained by Rietveld refinement of these patterns are summarized in Table 1. During the first hydrogenation, most of the $\mathrm{Mg}$ was converted into $\mathrm{MgH}_{2}$, while the nickel remained in its original form. Conversely, after the first desorption, most of the nickel was combined to form $\mathrm{Mg}_{2} \mathrm{NiH}_{0.3}$. The dehydrogenation reaction enabled the formation of this $\mathrm{Mg}_{2} \mathrm{NiH}_{0.3}$ phase at a temperature of $310^{\circ} \mathrm{C}$, which is much lower than the melting point of the eutectic composition $\left(506^{\circ} \mathrm{C}\right)$, presumably promoted by the mobility of magnesium and/or nickel atoms. The amount of hydrogen trapped as a solid solution in $\mathrm{Mg}_{2} \mathrm{NiH}_{0.3}$ which cannot be desorbed under $15 \mathrm{kPa}$ at $310^{\circ} \mathrm{C}$ and the 
remaining $5 \mathrm{wt}$ \% of $\mathrm{MgH}_{2}$ explain the slight irreversibility observed at the end of the desorption step for the two first cycles, in Figure 4a. After three hydrogen cycles, the $\mathrm{Mg}_{2} \mathrm{NiH}_{0.3}$ phase appeared well crystallized and the magnesium phase was fully desorbed.

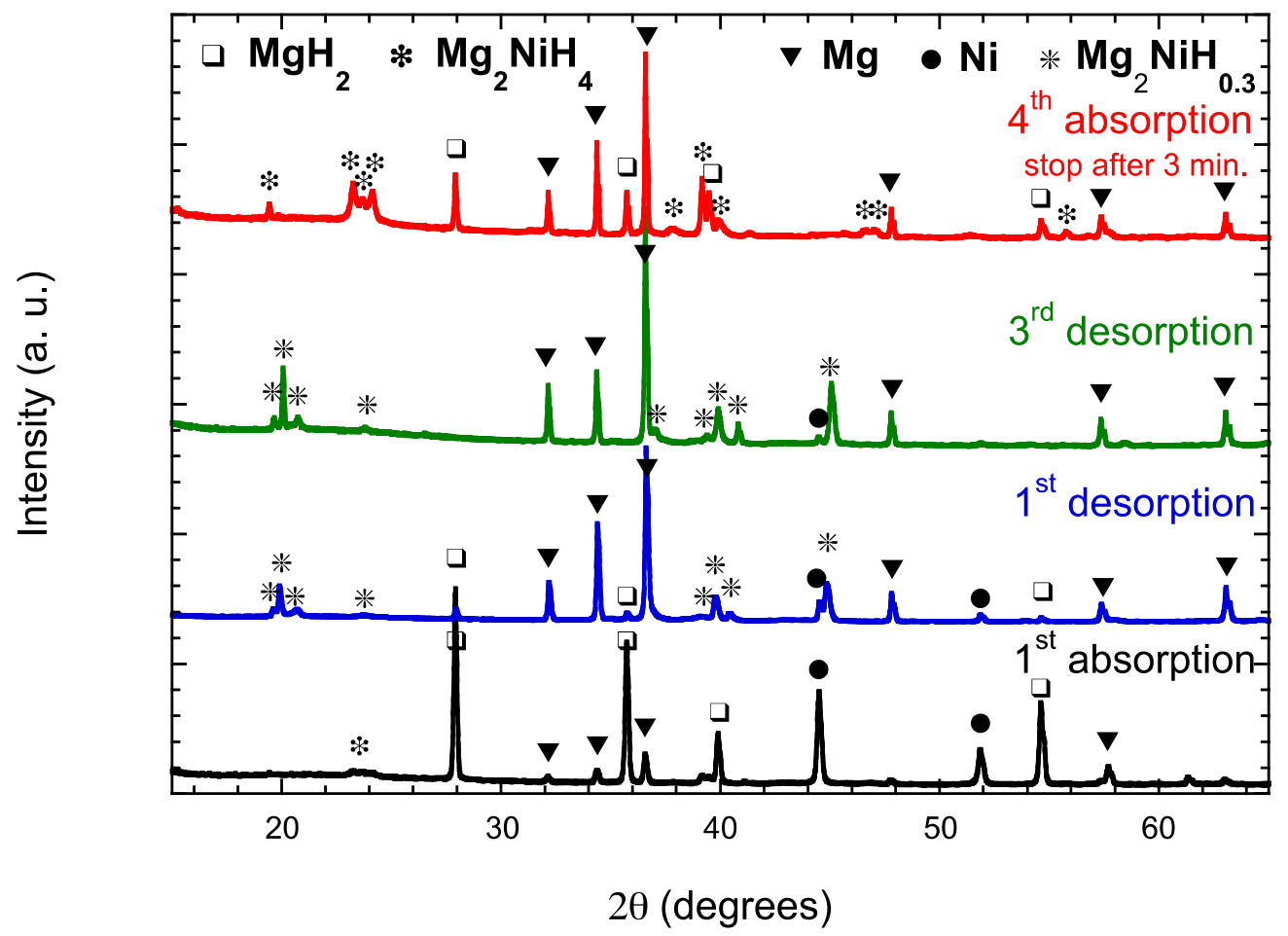

Figure 5. XRD patterns of the Mg-Ni sample forged at room temperature, in the following states: 1st absorption, 1st desorption, 3rd desorption, and 4th absorption stopped after $3 \mathrm{~min}$.

Table 1. Weight fraction (\%) of phases observed in samples forged at room temperature.

\begin{tabular}{ccccccc}
\hline & $\mathbf{M g}$ & $\mathbf{N i}$ & $\mathbf{M g}_{2} \mathbf{N i}$ & $\mathbf{M g}_{2} \mathbf{N i H}_{\mathbf{0}}$ & $\mathbf{M g H}_{2}$ & $\mathbf{M g}_{2} \mathbf{N i H}_{4}$ \\
\hline As forged & 80.3 & 19.7 & $<1$ & - & - & - \\
\hline 1st absorption & 6.5 & 28.5 & - & - & 63 & 2 \\
\hline 1st desorption & 66 & 3 & - & 26 & 5 & - \\
\hline 3rd desorption & 65 & 1 & - & 34 & - & - \\
\hline 4th abs. 3 min & 40 & - & - & 2 & 16 & 41 \\
\hline
\end{tabular}

In order to understand the two-stage behavior of the kinetics curves, the 4th absorption was stopped after 3 min only, by rapid cooling of the sample under hydrogen pressure. Most of the $\mathrm{Mg}_{2} \mathrm{NiH}_{0.3}$ phase was already transformed into $\mathrm{Mg}_{2} \mathrm{NiH}_{4}$ while less than one-third of the $\mathrm{Mg}$ was transformed into $\mathrm{MgH}_{2}$. The slow kinetics observed in the second stage of the reaction correspond to the hydrogenation of the remaining $\mathrm{Mg}$, which seems not so well activated.

\subsection{Mg-Ni Eutectic Composition Forged at Higher Temperatures}

In order to promote a homogeneous distribution of thin $\mathrm{Mg}_{2} \mathrm{Ni}$ particles into the $\mathrm{Mg}$ matrix, 4 samples of the same $\mathrm{Mg}-10.45$ at.\% Ni hypoeutectic composition were forged at increasing temperatures up to $530^{\circ} \mathrm{C}$. The thickness and the corresponding reduction ratio are reported in Table 2 for each sample. As expected, the reduction ratio increased with the temperature and reached $91 \%$ at $530{ }^{\circ} \mathrm{C}$. 
Table 2. Thickness, reduction ratio, and weight fraction (\%) of phases in as-forged samples.

\begin{tabular}{ccccccccc}
\hline \multirow{2}{*}{$\begin{array}{c}\text { Forging T } \\
\left({ }^{\circ} \mathbf{C}\right)\end{array}$} & \multirow{2}{*}{$\begin{array}{c}\text { Thickness } \\
(\mathbf{m m})\end{array}$} & $\begin{array}{c}\text { Reduction } \\
\text { Ratio (\%) }\end{array}$ & \multicolumn{2}{c}{$\mathbf{M g}$} & \multicolumn{3}{c}{$\mathbf{N i}$} & \multicolumn{2}{c}{$\mathbf{M g}_{2} \mathbf{N i}$} \\
\cline { 4 - 9 } & & & wt.\% & Strain (\%) & wt.\% & Strain (\%) & wt.\% & Strain (\%) \\
\hline $210{ }^{\circ} \mathrm{C}$ & 3.94 & 80.3 & 76.2 & 0.17 & 23.8 & 0.21 & - & - \\
$390{ }^{\circ} \mathrm{C}$ & 2.49 & 87.6 & 75.9 & 0.14 & 19.8 & 0.19 & 4.3 & 0.32 \\
$480{ }^{\circ} \mathrm{C}$ & 1.97 & 90.1 & 62.5 & 0.14 & 2.2 & 0.09 & 35.5 & 0.16 \\
$530{ }^{\circ} \mathrm{C}$ & 1.77 & 91.1 & 58.0 & 0.14 & - & - & 42 & 0.15 \\
\hline
\end{tabular}

Figure 6 shows the XRD patterns acquired on the upper horizontal surface of the samples forged at increasing temperatures. The relative intensities of the diffraction peaks indicate a strong texture along the c-axis of the $\mathrm{Mg}$ phase, especially for the sample forged at $210^{\circ} \mathrm{C}$. This texture tended, however, to decrease when the forging temperature increased. The weight fractions calculated from the XRD patterns (Figure 7) are reported for each phase in Table 2. Up to a temperature of $390^{\circ} \mathrm{C}$, the forging process did not produce significant amounts of $\mathrm{Mg}_{2} \mathrm{Ni}$. The microstructure was very similar to the one of the sample forged at room temperature, with agglomerated $\mathrm{Ni}$ particles embedded in $\mathrm{Mg}$ matrix (Figure $8 \mathrm{a}, \mathrm{b}$ ). The size of these Ni agglomerates, approximately $2 \mu \mathrm{m}$ in diameter, corresponds to the particle size of the Ni powder used as a precursor.
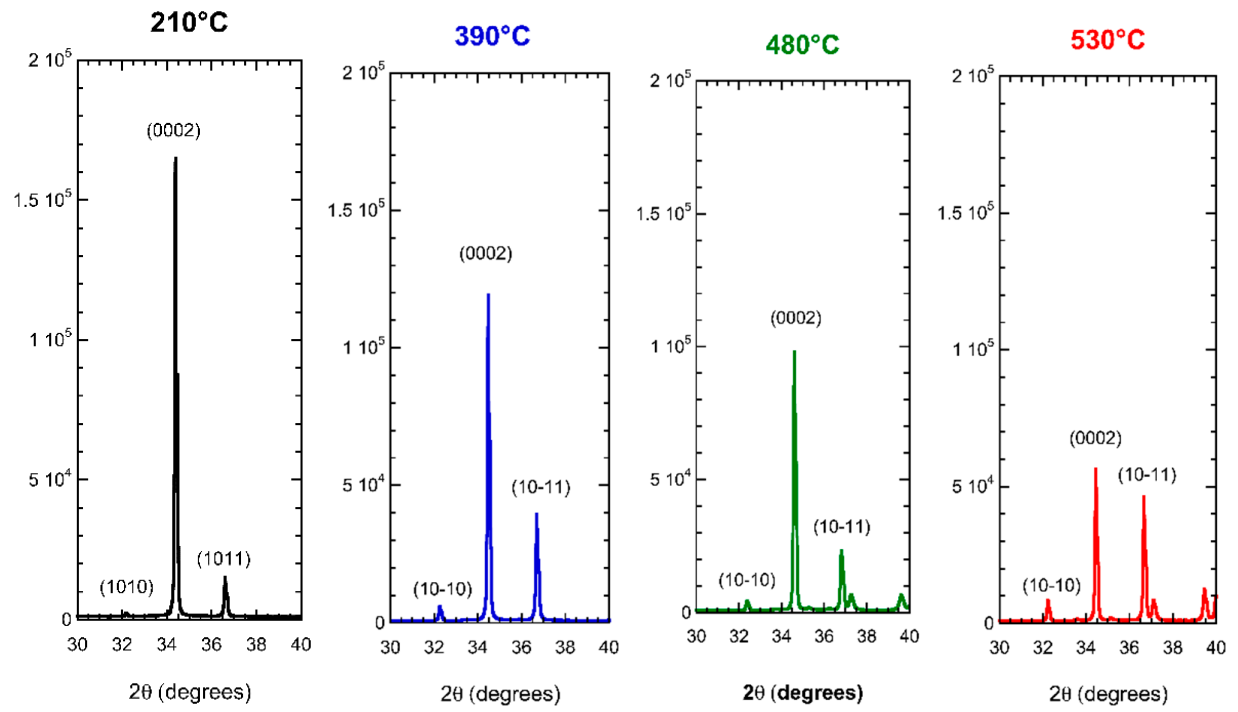

Figure 6. XRD patterns acquired on polished surfaces, on the upper horizontal surface of the $\mathrm{Mg}-\mathrm{Ni}$ samples forged at increasing temperatures.

Forging at $480{ }^{\circ} \mathrm{C}$ led to the formation of $\mathrm{Mg}_{2} \mathrm{Ni}$ coarse particles of about 20 to $50 \mu \mathrm{m}$ appearing in light grey in SEM Figure 8c, and containing Ni nodules remaining in their center (in white). Punctual EDX analyses performed on the light grey areas correspond exactly to the $\mathrm{Mg}_{2} \mathrm{Ni}$ nominal composition (Table 3), the dispersion between different points of measurements being very low. The fraction of $\mathrm{Mg}_{2} \mathrm{Ni}$ reached $35 \mathrm{wt} . \%$ (Table 2), while the expected amount would be $43 \mathrm{wt} . \%$ if all the nickel was recombined with magnesium. At higher magnification (Figure 8d), the dark grey areas observed inside the $\mathrm{Mg}_{2} \mathrm{Ni}$ particles reveal a specific microstructure characteristic of eutectic formation, indicating that partial melting occurred locally. To determine whether the formation of $\mathrm{Mg}_{2} \mathrm{Ni}$ can be attributed to the effect of fast deformation, or simply to the fact that the alloy was exposed to a high temperature, a control experiment of static annealing was performed at $480^{\circ} \mathrm{C}$ for $10 \mathrm{~min}$, which is the delay applied to stabilize the temperature before forging. XRD analysis of this sample revealed no trace of $\mathrm{Mg}_{2} \mathrm{Ni}$ after annealing (supplementary work). The formation of this phase indeed results from the fast forging itself, and is due to the heat released during the mechanical deformation, which induces an overpass of the melting temperature of the eutectic $\left(506^{\circ} \mathrm{C}\right)$ for a short time, as already reported in [27]. 


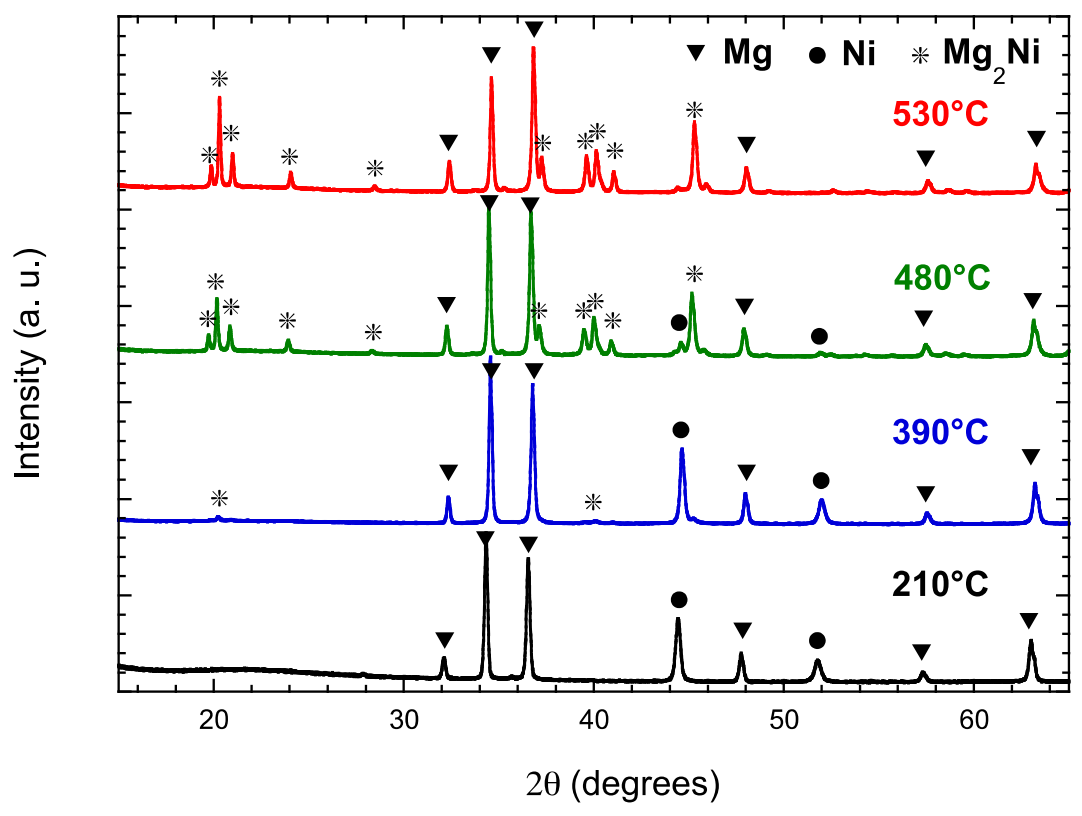

Figure 7. XRD patterns of Mg-Ni samples forged at increasing temperatures.
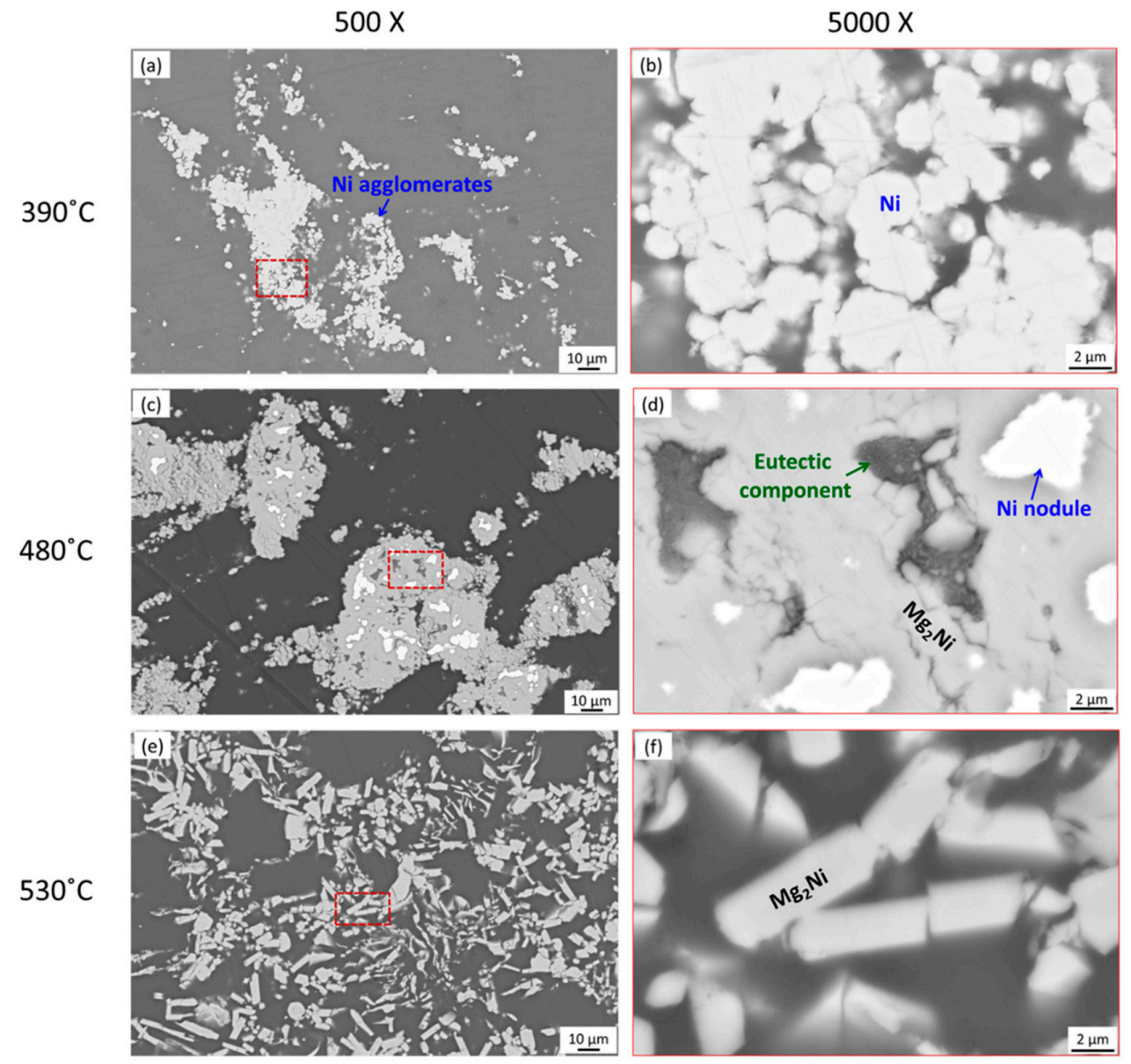

Figure 8. Back-scattered SEM images of the surface perpendicular to the forging direction of samples forged $(\mathbf{a}, \mathbf{b})$ at $390{ }^{\circ} \mathrm{C} ;(\mathbf{c}, \mathbf{d})$ at $480{ }^{\circ} \mathrm{C}$; and $(\mathbf{e}, \mathbf{f})$ at $530{ }^{\circ} \mathrm{C}$.

When forging is performed at $530{ }^{\circ} \mathrm{C}$, above the melting temperature of the eutectic composition, $\mathrm{Mg}_{2} \mathrm{Ni}$ formation occurs while heating the sample, as confirmed by the XRD pattern recorded after 
annealing a sample at $530^{\circ} \mathrm{C}$ for $10 \mathrm{~min}$ (supplementary work). After forging, both XRD (Table 2) and EDX analyses (Table 3) indicate a complete recombination of the $\mathrm{Ni}$ into $\mathrm{Mg}_{2} \mathrm{Ni}$. The microstructure observed by SEM (Figure 8e) reveals well-faceted and homogenously dispersed $\mathrm{Mg}_{2} \mathrm{Ni}$ plates of about $10 \mu \mathrm{m}$ length or more. This microstructure is completely different from what is observed at lower temperatures, as well as from the characteristic microstructure expected for a eutectic composition. Moreover, the $\mathrm{Mg}_{2} \mathrm{Ni}$ crystals appear fragmented (Figure $8 \mathrm{f}$ ), indicating that they were grown before applying the forging shock.

Table 3. Compositions of each phase (EDX analyses, at.\%).

\begin{tabular}{ccccccc}
\hline \multirow{2}{*}{ Forging $\mathbf{T}\left({ }^{\circ} \mathrm{C}\right)$} & \multicolumn{2}{c}{ Magnesium } & \multicolumn{2}{c}{ Nickel } & \multicolumn{2}{c}{$\mathbf{M g}_{2} \mathbf{N i}$} \\
& $\mathbf{M g}$ & $\mathbf{N i}$ & $\mathbf{M g}$ & $\mathbf{N i}$ & $\mathbf{M g}$ & $\mathbf{N i}$ \\
\hline $210^{\circ} \mathrm{C}$ & 99.6 & 0.4 & 2.3 & 97.7 & - & - \\
$390^{\circ} \mathrm{C}$ & 99.6 & 0.4 & 3.2 & 96.8 & - & - \\
$480^{\circ} \mathrm{C}$ & 99.6 & 0.4 & 2.8 & 97.1 & 66.7 & 33.3 \\
$530^{\circ} \mathrm{C}$ & 99.7 & 0.3 & - & - & 66.9 & 33.1 \\
\hline
\end{tabular}

Whatever the forging temperature, the EDX analyses indicate the presence of a small amount of $\mathrm{Ni}$ in the Mg phase and some Mg in the Ni phase (Table 3). The accuracy of the EDX measurements does not allow us to state whether these elements are indeed present in solid solution. However, the cell parameters calculated from XRD do not indicate significant deviations from the pure metallic phases and these observations most probably result from the large probe area.

Hydrogen pressure cycles were performed on each sample at the same pressures (2 MPa and $150 \mathrm{kPa}$ ) but at $325^{\circ} \mathrm{C}$ instead of $310^{\circ} \mathrm{C}$, because of the poor reactivity at $310^{\circ} \mathrm{C}$ of the samples forged in temperature. During the first absorption (Figure 9a), the kinetic appeared very slow for the sample forged at $530{ }^{\circ} \mathrm{C}$, and no absorption was observed for the one forged at $480{ }^{\circ} \mathrm{C}$. On the other hand, the sample forged at $210^{\circ} \mathrm{C}$ absorbed about $1 \mathrm{wt} . \%$ in $30 \mathrm{~min}$. Low-temperature forging and even RT forging are then more effective for activation. This behavior was not expected since the samples forged at RT or low temperature did not contain $\mathrm{Mg}_{2} \mathrm{Ni}$ phase. However, as reported in Table 2, a decrease of the internal strains with the increase of the temperature was observed in the three phases. The brittle-to-ductile transition temperature of magnesium is of about $225-250{ }^{\circ} \mathrm{C}$ [31]. Thus, forging in the brittle state induces a higher amount of internal strains, and probably the formation of cracks and/or structural defects that promote the diffusion of hydrogen into the bulk material, while forging in the ductile state reduces porosity and does not induce cracks. The higher texture observed when forging at lower temperatures could also induce a faster diffusion of hydrogen into the material, as this texture corresponds to the best orientation for hydrogen sorption properties [8].

Absorption kinetics increased rapidly during the following pressure cycles (Figure $9 \mathrm{~b}$ ) to converge to the same curves after about 12 cycles (Figure 9c), whatever the forging temperature. As for the sample forged at room temperature, the formation of solid solution $\mathrm{Mg}_{2} \mathrm{NiH}_{0.3}$ induced a slight irreversibility at the end the first cycles (not shown here). This irreversibility was no more visible at the end of the third cycles (Figure $9 b$ ), which means that $\mathrm{Ni}$ was already fully recombined as $\mathrm{Mg}_{2} \mathrm{NiH}_{0.3}$ at the end of the second cycles (the "zero" reference for the uptake was reinitialized before each cycle). Again, a two-stage behavior appeared progressively during the absorption, with a very fast kinetic at the beginning of the reaction (about $2 \mathrm{wt} . \%$ in a few seconds) followed by a much slower absorption and a hydrogen uptake limited to $3.5 \mathrm{wt} . \%$ in $1 \mathrm{~h}$. The hydrogenation of the $\mathrm{Mg}_{2} \mathrm{NiH}_{0.3}$ phase into $\mathrm{Mg}_{2} \mathrm{NiH}_{4}$ corresponds to a maximum uptake of $1.3 \mathrm{wt} . \%$. This means that the first absorption stage was not only due to the hydrogenation of this phase, and that at least a fraction of the pure magnesium phase remained activated after a large number of cycles. Surprisingly, desorption kinetics became faster when forging at higher temperatures (Figure 9c). This behavior could result from a better adherence between $\mathrm{Mg}$ and $\mathrm{Mg}_{2} \mathrm{Ni}$ particles when the $\mathrm{Mg}_{2} \mathrm{Ni}$ phase is formed directly during the forging process. This would enable a catalytic role of the $\mathrm{Mg}_{2} \mathrm{NiH}_{0.3}$ or $\mathrm{Mg}_{2} \mathrm{NiH}_{4}$ during the dehydrogenation of the $\mathrm{MgH}_{2}$ phase. 


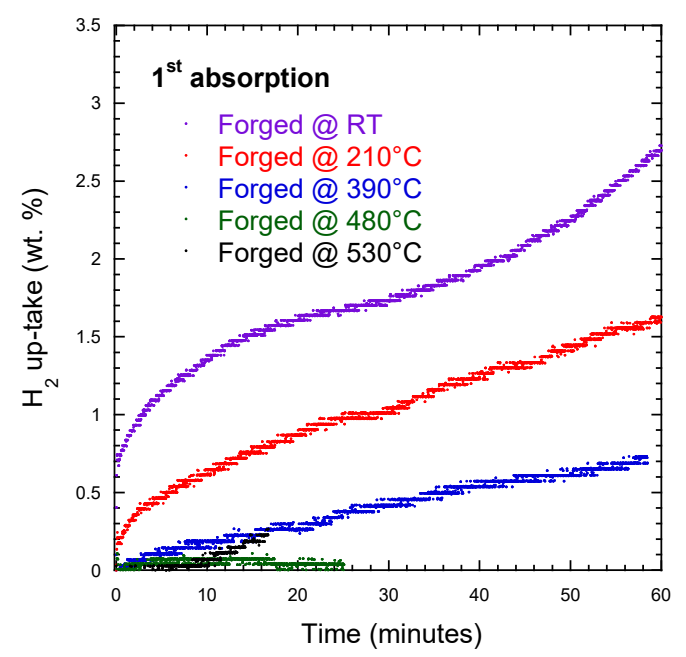

(a)

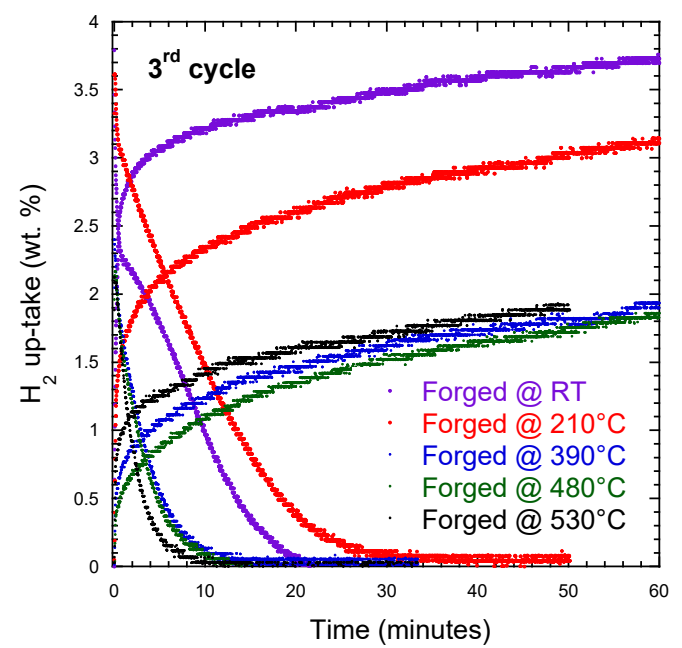

(b)

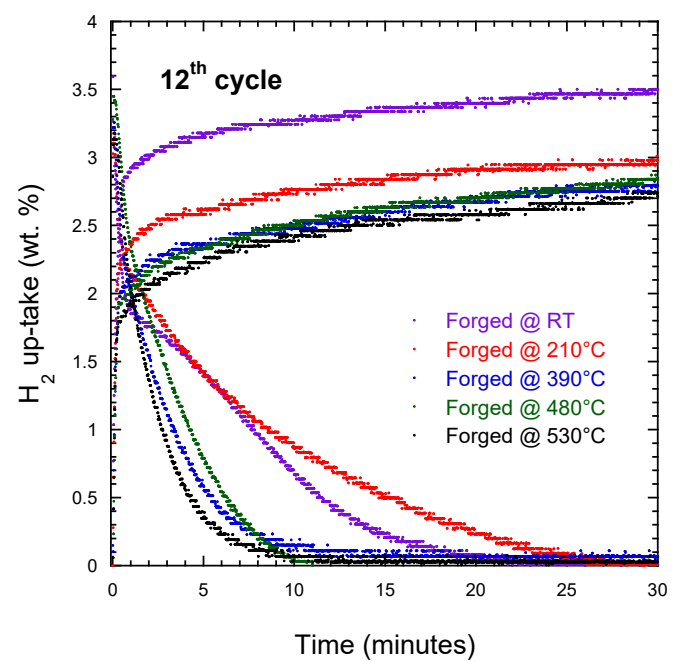

(c)

Figure 9. Absorption and desorption kinetics recorded on samples forged at RT, $210{ }^{\circ} \mathrm{C}, 390{ }^{\circ} \mathrm{C}, 480{ }^{\circ} \mathrm{C}$, and $530^{\circ} \mathrm{C}$. (a) 1st absorption, (b) 3rd cycle, and (c) 12th cycle. Hydrogen pressure cycles were applied at $325^{\circ} \mathrm{C}$, with respectively $2 \mathrm{MPa}$ and $150 \mathrm{kPa}$ for absorption and desorption steps. 
EBSD and in situ neutron diffraction experiments are in progress in order to better analyze the induced texture, to understand the two-step behavior of the absorption reaction, and to seek to increase the part of magnesium that remains activated after further hydrogen cycles.

\section{Conclusions}

Magnesium is a promising material for hydrogen storage but its use-at least in its unprocessed form-is hampered by slow sorption kinetics. Here, we show that Mg sample forging leads to improved properties but sorption kinetics remain rather slow even after several hydrogen cycles (almost $2 \mathrm{~h}$ to desorb at $360^{\circ} \mathrm{C}, 150 \mathrm{kPa}$ ). In contrast, introducing nickel into the metal sample drastically improves its sorption properties.

Low-temperature forging. Forging Mg-Ni samples in the brittle state $\left(T<225-250{ }^{\circ} \mathrm{C}\right)$ is found to be the most efficient method to activate samples (first absorption). Considering that no $\mathrm{Mg}_{2} \mathrm{Ni}$ forms upon forging at such temperature, this activation improvement is assumed to result from the forging-induced texture along the $\mathrm{c}$ axis together with the formation of internal strains, fractures, and/or structural defects that promote hydrogen diffusion through the bulk material. The unalloyed nickel combines into $\mathrm{Mg}_{2} \mathrm{NiH}_{0.3}$ during the first desorption reaction. Considering the slow atomic mobility at the desorption temperature $\left(T=325^{\circ} \mathrm{C}\right)$, the formation mechanism of $\mathrm{Mg}_{2} \mathrm{NiH}_{0.3}$ remains to be understood.

High-temperature forging. Forging above $\mathrm{T}=400{ }^{\circ} \mathrm{C}$ leads to the formation of $\mathrm{Mg}_{2} \mathrm{Ni}$ during the process with resulting microstructures strongly dependent on the forging temperature. Above the eutectic temperature, the growth of $\mathrm{Mg}_{2} \mathrm{Ni}$ crystallites occurs prior to the forging deformation, during the thermal stabilization. In contrast, as the forging temperature is decreased, the formation of $\mathrm{Mg}_{2} \mathrm{Ni}$ is likely to result from solid-state reaction as a result of local (i.e., spatially restricted) alloying/recrystallization during the mechanical deformation. However, regardless of the forging temperature, despite different resulting microstructures, similar sorption behaviors are observed after a few cycles. These results, which indicate that the forging temperature is mainly a critical parameter for the activation process, are promising since forging processes can be easily scaled up to produce very large sample amounts. At this stage, the hydrogen capacity of samples obtained using such techniques does not compete with HEBM. However, this simple and economical process is a mature technology that enables mass production without handling pyrophoric powders.

Author Contributions: Conceptualization P.d.R., D.F. and N.S.; processing by Fast Forging, P.d.R. and J.W.; investigation and analysis, P.d.R., J.W. and M.B.; writing-original draft preparation, P.d.R., D.F., N.S., J.W. and L.L.; writing-review and editing, P.d.R. and L.L. All authors have read and agreed to the published version of the manuscript.

Funding: This research was funded by the CDP Eco-SESA, from the University Grenoble Alpes IDEX.

Acknowledgments: E. Verloop is acknowledged by the authors for technical support.

Conflicts of Interest: The authors declare no conflict of interest.

\section{References}

1. Yartys, V.A. Magnesium based materials for hydrogen based energy storage: Past, present and future. Int. J. Hydrogen Energy 2019, 44, 7809-7859. [CrossRef]

2. Liang, G.; Huot, J.; Boily, S.; Van Neste, A.; Schulz, R. Hydrogen storage properties of the mechanically milled $\mathrm{MgH}_{2}-\mathrm{V}$ nanocomposite. J. Alloy. Comp. 1999, 291, 295-299. [CrossRef]

3. Oelerich, W.; Klassen, T.; Bowmann, R. Metal oxides as catalysts for improved hydrogen sorption in nanocrystalline Mg-based materials. J. Alloy. Comp. 2001, 315, 237-279. [CrossRef]

4. Miraglia, S.; de Rango, P.; Rivoirard, S.; Fruchart, D.; Charbonnier, J.; Skryabina, N. Hydrogen sorption properties of compounds based on bcc $\mathrm{Ti}_{1-\mathrm{x}} \mathrm{V}_{1-\mathrm{y}} \mathrm{Cr}_{1+\mathrm{x}+\mathrm{y}}$ alloys. J. Alloy. Comp. 2016, 536, 1-6. [CrossRef]

5. Gerar, N.; Ono, S. Hydride formation and decomposition kinetics. In Hydrogen in Intermetallic Compounds; Schlapbach, L., Ed.; Springer: Berlin/Heidelberg, Germany, 1992. 
6. Skripnyuk, V.M.; Rabkin, E.; Estrin, Y.; Lapovok, R. Improving hydrogen storage properties of magnesium based alloys by equal channel angular. Int. J. Hydrogen Energy 2009, 34, 6320-6324. [CrossRef]

7. Huot, J.; Fruchart, D.; Skryabina, N. Application of Severe Plastic Deformation Technics to Magnesium for Enhanced Hydrogen Sorption Properties. Metals 2012, 2, 329-343. [CrossRef]

8. Jorge, A.M., Jr.; Prokofiev, E.; de Lima, G.F.; Rauch, E.; Veron, M.; Botta, W.J.; Kawasaki, M.; Langdon, T.G. An investigation of hydrogen storage in a magnesium-based alloy processed by equal-channel angular pressing. Int. J. Hydrogen Energy 2013, 38, 8306-8312. [CrossRef]

9. Skryabina, N.; Medvedeva, N.; Gabov, A.; Fruchart, D.; Nachev, S.; de Rango, P. Impact of Severe Plastic Deformation on the stability of $\mathrm{MgH}_{2}$. J. Alloy. Comp. 2015, 645, S14-S17. [CrossRef]

10. Skryabina, N.; Aptukov, V.; Romanov, P.; Fruchart, D.; de Rango, P.; Girard, G.; Grandini, C.; Sandim, H.; Huot, J.; Lang, J.; et al. Microstructure optimisation of Mg-Alloys by the ECAP process including numerical simulation, SPD treatments, characterization and hydrogen sorption properties. Molecules 2018, $24,89$. [CrossRef] [PubMed]

11. Huot, J.; Amira, S.; Lang, J.; Skryabina, N.; Fruchart, D. Improvement of hydrogen properties of magnesium alloys by cold rolling and forging. Mater. Sci. Eng. 2014, 63, 012114. [CrossRef]

12. Edalati, K.; Yamamoto, A.; Horita, Z.; Ishihara, T. High pressure torsion of pure magnesium: Evolution of mechanical properties, microstructures and hydrogen storage capacity with equivalent strain. Scr. Mater. 2011, 64, 880-883. [CrossRef]

13. Panda, S.; Fundenberger, J.J.; Zhao, Y.Z.; Toth, L.; Grosdidier, T. Effect of initial powder type on the hydrogen storage properties of high-pressure torsion consolidated Mg. Int. J. Hydrogen Energy 2017, 42, 22438-22448. [CrossRef]

14. Jorge, A.M., Jr.; de Lima, G.F.; Triques, M.R.M.; Botta, W.J.; Kiminami, C.S.; Noguiera, R.P.; Yavari, A.R.; Langdon, T.G. Correlation between hydrogen storage properties and texture induced in magnesium through ECAP and cold rolling. Int. J. Hydrogen Energy 2014, 39, 3810-3821. [CrossRef]

15. Jorge, A.M., Jr.; Prokofiev, E.; Triques, M.R.M.; Roche, V.; Botta, W.B.; Kiminami, C.S.; Raab, G.I.; Valiev, R.Z.; Langdon, T.G. Effect of cold rolling on the structure and hydrogen properties of AZ91 and AM60D magnesium alloys processed by ECAP. Int. J. Hydrogen Energy 2017, 42, 21822-21831. [CrossRef]

16. Asselli, A.C.; Leiva, D.R.; Huot, J.; Kawasaki, M.; Langdon, T.G.; Botta, W.J. Effects of equal-channel angular pressing and accumulative roll-bonding on hydrogen storage properties of a commercial ZK60 magnesium alloy. Int. J. Hydrogen Energy 2015, 40, 16971-16976. [CrossRef]

17. Asselli, A.A.C.; Hébert, N.B.; Huot, J. The role and morphology and severe plastic deformation on the hydrogen storage properties of magnesium. Int. J. Hydrogen Energy 2014, 39, 12778-12783. [CrossRef]

18. Zou, J.; Sun, H.; Zeng, X.; Ding, W. Preparation and hydrogenation storage properties of Mg-rich Mg-Ni ultrafine particles, Hindawi Publishing Corporation. J. Nanomater. 2012, 2012, 1-8.

19. Skripnyuk, V.M.; Buchman, E.; Rabkin, E.; Estrin, Y.; Popov, M.; Jorgensen, S. The effect of equal channel angular pressing on hydrogen storage properties of a eutectic Mg-Ni alloy. J. Alloy. Comp. 2007, 436, 99-106. [CrossRef]

20. Popilevsky, L.; Skripnyuk, V.M.; Estrin, Y.; Dahle, A.; Mirabile Gattia, D.; Montone, A.; Rabkin, E. Hydrogen-induced microstructure evolution in as cast and severely deformed $\mathrm{Mg}-10 \mathrm{wt}$ \% Ni alloy. Int. J. Hydrogen Energy 2013, 38, 12103-12114. [CrossRef]

21. Révész, A.; Gajdics, M.; Varga, L.K.; Krallics, G.; Péter, L.; Spassov, T. Hydrogen storage of nanocrystalline $\mathrm{Mg}-\mathrm{Ni}$ alloy processed by equal-channel angular pressing and cold rolling. Int. J. Hydrogen Energy 2014, 39, 9911-9917. [CrossRef]

22. Hongo, T.; Edalati, K.; Arita, M.; Matsuda, J.; Akiba, E.; Horita, Z. Significance of grain boundaries and stacking faults on hydrogen storage properties of $\mathrm{Mg}_{2} \mathrm{Ni}$ intermetallics processed by high-pressure torsion. Acta Mater. 2015, 92, 46-54. [CrossRef]

23. Leiva, D.R.; Floriano, R.; Huot, J.; Jorge Jr, A.M.; Bolfarini, C.; Kiminami, C.S.; Ishikawa, T.T.; Botta, W.J. Nanostructured $\mathrm{MgH}_{2}$ prepared by cold rolling and cold forging. J. Alloy. Comp. 2011, 509S, S444-S448. [CrossRef]

24. Asselli, A.A.C.; Leiva, D.R.; Cozentino, G.H.; Floriano, R.; Huot, J.; Ishikawa, T.T.; Botta, W.J. Hydrogen storage properties of $\mathrm{MgH}_{2}$ processed by cold forging. J. Alloy. Comp. 2014, 615, S719-S724. [CrossRef] 
25. Leiva, D.R.; Jorge, A.M., Jr.; Ishikawa, T.T.; Huot, J.; Fruchart, D.; Miraglia, S.; Kiminami, C.S.; Botta, W.J. Nanoscale grain refinement and $\mathrm{H}$-sorption properties of $\mathrm{MgH}_{2}$ processed by High-Pressure torsion and other mechanical routes. Adv. Eng. Mater. 2010, 12, 8. [CrossRef]

26. De Rango, P.; Fruchart, D.; Aptukov, V.; Skryabina, N. Fast forging: A new method to synthesize Mg-based alloys for hydrogen storage. Int. J. Hydrogen Energy 2020, 45, 7912-7916. [CrossRef]

27. Skryabina, N.; Aptukov, V.; de Rango, P.; Fruchart, D. Effect of temperature on fast forging process of Mg-Ni samples for fast formation of $\mathrm{Mg}_{2} \mathrm{Ni}$ for hydrogen storage. Int. J. Hydrogen Energy 2020, 45, 3008-3015. [CrossRef]

28. Popa, I.; de Rango, P.; Fruchart, D.; Rivoirard, S. High-speed $\mathrm{NdFe}_{12-\mathrm{x}} \mathrm{V}_{\mathrm{x}}$ compounds for bonded magnets. J. Mag. Mater. 2002, 242-245, 1388-1390. [CrossRef]

29. Rodriguez-Carvajal, J. Recent Developments of the Program FULLPROF. Comm. Powder Diffr. Newsl. 2001, 26, 12-19.

30. Garrier, S.; Chaise, A.; de Rango, P.; Marty, P.; Delhomme, B.; Fruchart, D.; Miraglia, S. MgH $_{2}$ intermediate scale tank test under various experimental conditions. Int. J. Hydrogen Energy 2011, 36, 9719-9726. [CrossRef]

31. Al-Salmman, T.; Gottstein, G. Dynamic recrystallization during high temperature deformation of magnesium. Mater. Sci. Eng. A 2008, 490, 411-420. [CrossRef]

(C) 2020 by the authors. Licensee MDPI, Basel, Switzerland. This article is an open access article distributed under the terms and conditions of the Creative Commons Attribution (CC BY) license (http://creativecommons.org/licenses/by/4.0/). 